\title{
Detecção de sífilis por ensaios de ELISA e VDRL em doadores de sangue do Hemonúcleo de Guarapuava, Estado do Paraná
}

\author{
Syphilis detection using ELISA and VDRL tests on blood donors \\ at the blood center of Guarapuava, State of Paraná
}

\author{
Viviane Matoso de Oliveira $^{1}$, Izabel Cristina Verdasca ${ }^{2}$ e Marta Chagas Monteiro ${ }^{1}$
}

\begin{abstract}
RESUMO
O objetivo desse estudo foi avaliar a soroprevalência de sífilis em 5.752 doadores de sangue atendidos no Hemonúcleo de Guarapuava-PR, em 2006. As taxas de positividade foram de 2,1\% pelo teste de ensaio imunoenzimático e 0,2\% pelo Veneral Disease Research Laboratory, mostrando baixa prevalência de sífilis nos indivíduos que procuraram este banco de sangue.
\end{abstract}

Palavras-chaves: Sífilis. Treponema pallidum. Ensaio imunoenzimático. Veneral Disease Research Laboratory. Doadores de sangue.

\section{ABSTRACT}

The aim of this study was to evaluate the syphilis seroprevalence among 5,752 blood donors who were attended at the blood center of Guarapuava, State of Paraná, in 2006. The seropositivity rates were 2.1\% for enzyme Linked Immuno Sorbent Assay and 0.2\% for Veneral Disease Research Laboratory, thus showing low prevalence of syphilis among the individuals who came to this blood bank.

Key-words: Syphilis. Treponema pallidum. Linked immuno sorbent assay. Veneral Disease Research Laboratory. Blood donors.

A sífilis é uma doença infecciosa crônica causada pelo Treponema pallidum ${ }^{17}$. Em alguns países, como o Brasil, é considerada como um dos principais problemas de Saúde Pública ${ }^{4}$, similar a outras doenças infecciosas emergentes no país $^{14}$. De acordo com a Organização Mundial de Saúde, a estimativa é de aproximadamente 12 milhões de novos casos de pessoas infectadas por ano com alguma doença relacionada ao sexo, dentre as quais a sífilis apresenta grande representatividade? Segundo a Organização Mundial de Saúde (OMS), é a segunda ou terceira causa de úlcera genital ${ }^{3}$. Em 2003, estimou-se 843.300 o número de casos de sífilis no Brasil ${ }^{3}$, cujos mecanismos de transmissão podem ser por contato direto com as lesões de sífilis na pele, via transplacentária ou ainda transfusões sangüíneas ${ }^{11}$. No Brasil, a Portaria 1376/93, reforçada pela Resolução RDC 343/2002, preconizada pela ANVISA (Agência Nacional de Vigilância Sanitária) determinou a obrigatoriedade da realização de testes de triagem sorológica nos serviços de hemoterapia para sífilis, doença de Chagas, hepatite B e C, AIDS, HTLV e malária ${ }^{1}$. Atualmente, a pesquisa para sífilis é realizada combinando testes específicos e não específicos, e a maioria laboratórios têm optado pelo Veneral Disease Research Laboratory (VDRL) e o ensaio imunoenzimático (ELISA) por serem de fácil execução. Nesse sentido, esse estudo teve por objetivo avaliar a positividade para sífilis, através dos métodos de ELISA e VDRL, em doadores de sangue no Hemonúcleo de Guarapuava, Estado do Paraná. A partir desses dados, identificar a soroprevalência dessa doença nessa população.

Foram analisados 5.752 prontuários de doadores de sangue do Hemonúcleo de Guarapuava/PR, do período de janeiro a dezembro de 2006, que estavam cadastrados no Sistema HEMOVIDA $^{\circledR}$ e com resultados descritos no livro de registros do Hemonúcleo. Dos prontuários foram analisados idade e sexo dos doadores de sangue, cujas sorologias foram positivas por ELISA e/ ou VDRL. Para o imunodiagnóstico de sífilis, 5.752 amostras foram analisadas por meio de teste treponêmico ELISA (Trepanostika ${ }^{\circledR}$ TP recombinant). As amostras reagentes no ELISA foram, em seguida, analisadas por meio de teste não treponêmico, VDRL (RPR LABORCLIN/BRÁS ${ }^{\circledR}$ ). 0 trabalho foi aprovado pelo Comitê Permanente de Ética em Pesquisa Envolvendo Seres Humanos da Universidade Estadual do Centro-Oeste, PR.

A Tabela 1 mostra que dos 5.752 doadores de sangue, $122(2,1 \%)$ apresentavam sorologia positiva aos anticorpos antiTreponema por ELISA, com $76.3 \%$ das amostras com absorbância maior que 2,000. Das 122 amostras, 84 (68,8\%) pertenciam a

\footnotetext{
1. Departamento de Farmácia, Universidade Estadual do Centro-Oeste; Guarapuava, PR. 2. Setor de sorologia, Hemonúcleo de Guarapuava, PR.

Endereço para correspondência: Dra. Marta Chagas Monteiro. Dept ${ }^{0}$ de Farmácia/UniCENTRO. Rua Simeão Camargo de Sá 3 , Bairro Cascavel, 85040-080 Guarapuava, PR.

Tel: 5542 3629-8137

e-mail: martachagas2@yahoo.com.br

Recebido para publicação em 11/10/2007

Aceito em 15/07/2008
} 
Tabela 1 - Distribuição por amostra reagente ou não reagente para sífilis pelo teste de ELISA e/ou VDRL e soroprevalência de sífilis nos doadores do Hemonúcleo de Guarapuava/PR.

\begin{tabular}{|c|c|c|c|c|c|c|c|c|}
\hline \multirow[t]{2}{*}{ Doadores } & \multicolumn{2}{|c|}{ ELISA } & \multicolumn{2}{|c|}{ VDRL } & \multicolumn{2}{|c|}{ ELISA/VDRL } & \multicolumn{2}{|c|}{ Soroprevalência } \\
\hline & $\mathrm{n} / \mathrm{N}^{*}$ & $\%$ & $\mathrm{n} / \mathrm{N}^{*}$ & $\%$ & $\mathrm{n} / \mathrm{N}^{*}$ & $\%$ & $\mathrm{n} / \mathrm{N}^{*}$ & $\%$ \\
\hline Reagentes & $122 / 5752$ & 2,1 & $9 / 5752$ & 0,2 & $9 / 122$ & 7,4 & $122 / 5752$ & 2,1 \\
\hline Não-reagentes & $5.630 / 5752$ & 97,9 & $5.743 / 5752$ & 99,8 & $113 / 122$ & 92,6 & - & . \\
\hline
\end{tabular}

$\mathrm{n} / \mathrm{N}^{*}=$ número de positivos sobre o número total de amostras testada

ELISA: ensaio imunoenzimático, VDRL: Veneral Disease Research Laboratory

indivíduos do sexo masculino e 38 (31,2\%) feminino, entre a faixa etária 20-40 anos (44,3\% - 54 indivíduos) e 41 e 61 anos (55,7\% - 68 indivíduos). Das amostras positivas para sífilis por ELISA, nove também foram positivas para anticorpos não treponêmicos por VDRL, representando 7,4\% das 122 amostras reativas por ELISA ou $0,2 \%$ das 5.752 amostras totais de doadores que procuraram o Hemonúcleo de Guarapuava no ano de 2006. Além disso, das nove amostras, 5 (55,5\%) apresentaram positividade com título $1 / 2$, três $(33,3 \%)$ com o título $1 / 4$ e uma $(11,1 \%)$ com o título $1 / 32$. Dessas amostras, quatro $(44,4 \%)$ pertenciam a indivíduos de sexo feminino e cinco $(55,6 \%)$ masculino entre a faixa etária de 20 e 61 anos. Com isso, a soroprevalência detectada foi de 2,1\% (122) no total de doadores que procuraram o Hemonúcleo de Guarapuava, PR o ano de 2006. No Brasil, infecções por sífilis têm mostrado ascensões evidentes, refletindo na crescente incidência da sífilis congênita no país, estimada em mais de 130 mil casos anuais 5 .

Em 1999, a Organização Mundial de Saúde (OMS) estimou 340 milhões de casos novos por ano de DST curáveis (sífilis, gonorréia, clamídia, tricomoníase) em todo o mundo, entre indivíduos de 15 e 49 anos, com 10 a 12 milhões destes casos ocasionados no Brasil ${ }^{6}$. Nesse sentido, nossos dados foram compatíveis aos valores notificados de sífilis congênita, no Estado do Paraná, pelo SINAN, que registrou $1,17 \%$ do total de 219 casos notificados na Região Sul do País, em 2004 ${ }^{10}$. Segundo o Ministério da Saúde, 5.710 casos de sífilis foram notificados em 2005, mas estima-se que o número real seja de 12 mil casos/ ano, fato ocorrido devido à subnotificação de casos de sífilis no país ${ }^{10}$. Alguns estudos realizados em Bancos de Sangue de outras regiões relataram índices similares de sífilis em doadores de sangue, Salles e cols ${ }^{13}$ relataram que a positividade para sífilis em doadores se sangue provenientes da Fundação Pró-sangue - Hemocentro de São Paulo, no período de 1991 a 2001, foi de $2,7 \%$ quando diagnosticada pelo método de ELISA, $0,3 \%$ por VDRL e $1,8 \%$ por ELISA e VDRL simultaneamente, em 1991. Taxas que até 0 ano de 2001 ficaram bastante reduzidas, com positividade de $0,84 \%$ por ELISA, $0,1 \%$ VDRL e $0,3 \%$ por ELISA e VDRL. Os valores percentuais de reatividade detectadas por diferentes testes treponêmicos e não treponêmicos diferem bastante entre os Bancos de Sangue entre as diferentes regiões ${ }^{27812} 16$.

Uma problemática importante no diagnóstico da sífilis e outras infecções é a constante troca da marca dos kits utilizados para os testes de triagem sorológica, em função das normas de licitação que regem a compra de produtos nos bancos de sangue públicos. Embora sejam utilizados testes com alta sensibilidade e especificidade, cada marca pode gerar resultados falso-positivos em amostras diferentes, acarretando num somatório de resultados falso-positivos quando a marca dos reagentes é frequentemente trocada, o que aumenta a chance de um doador apresentar reação cruzada a pelo menos uma das marcas utilizadas ${ }^{13}$.

Recentemente, Sáez-Alquézar e cols ${ }^{12}$ demonstraram 0 desempenho de alguns testes sorológicos treponêmicos e não treponêmicos de diferentes marcas comerciais para sífilis, relatando que das 2.990 amostras de doadores de sangue do laboratório Hemo-Life, do período de março a maio de 2005 , $1,7 \%$ foram positivas pelo teste ELISA Recombinante, $0,4 \%$ por VDRL Bras Laborclin, com títulos variando de 1/2 até 1/8. Dados que fortalecem os nossos resultados, cuja reatividade foi de 2,1\% das amostras por ELISA Recombinante e 0,2\% por VDRL Bras Laborclin, com títulos variando de $1 / 2$ a 1/32. A baixa titulação das amostras reativas por VDRL nesse trabalho, pode ser explicada pelo fato que o diagnóstico laboratorial da sífilis depende da sua fase de infecção, nesse sentido, as dosagens quantitativas do VDRL expressas em títulos, em geral se elevam até o estágio secundário da sífilis. Sendo que, títulos baixos podem significar doença muito recente ou muito antiga, tratada ou nã $0^{4}{ }^{15}$. Com isso, os doadores que apresentaram positividade nesse estudo podem enquadrar-se em um desses grupos de pacientes com VDRL e ELISA positivos: a) sem história prévia de sífilis, que são tidos como portadores da sífilis latente tardia ou; b) com história prévia de sífilis de até 12 meses e que apresentam VDRL com titulação inferior ou igual a 1/8 que são classificados como portadores da sífilis latente precoce ${ }^{6}$. A partir desses dados, podemos sugerir que 8 (89\%) das 9 amostras positivas pelo ELISA e VDRL analisadas nesse estudo, enquadram-se na descrição de pacientes que estão em fase latente da sífilis, visto suas amostras sanguíneas serem inicialmente reativas pelo ELISA e em seguida positivas pelo teste de VDRL, com títulos inferiores a 1/8. Outros fatores que explicam a baixa positividade de sífilis evidenciada nesse estudo são: a) introdução de um sistema informatizado em rede em 1994, que impediu novas doações por indivíduos com sorologia anteriormente reativa a um ou mais dos agentes etiológicos; b) a automação dos testes laboratoriais, iniciada em 1991 com a utilização de pipetadores automáticos, chegando à automação completa em 1999; c) a introdução de padrões de qualidade em 1998; d) campanhas educativas que aumentaram, sobremaneira, a porcentagem de doadores de repetição ${ }^{13}$. Em conclusão, nossos dados mostraram baixos índices de positividade para sífilis, além de evidenciar uma baixa $(2,1 \%)$ prevalência dessa doença entre os indivíduos que procuraram o serviço de doação de sangue no Hemonúcleo de Guarapuava/PR, em 2006. Tais fatos refletem a competência dos profissionais responsáveis e o sucesso de um trabalho amplo, que abrange desde a triagem clínica à laboratorial, tendo como resultado final o aumento da qualidade do sangue disponível para transfusão. 


\section{REFERÊNCIAS}

1. Agência Nacional de Vigilância Sanitária (ANVISA). Sangue e hemoderivados. Legislação. Disponível em: http://www.anvisa.gov.br/e-legis/Acessado em $10 / 06 / 2008$.

2. Andrade ALSS, Martelli CMT, Pinheiro ED, Santana CL, Borges FP, Zicker F Rastreamento sorológico para doenças infecciosas em banco de sangue como indicador de morbidade populacional. Revista de Saúde Pública 23: 20-25, 1989.

3. Avelleira JCR, Bottino G. Sífilis: diagnóstico, tratamento e controle. Anais Brasileiros de Dermatologia 81: 111-126, 2006.

4. Barsanti C, Valdetaro F, Diniz EMA, Succi RCM. Diagnóstico de sífilis congenital: comparação entre testes sorológicos na mãe no recém-nascido. Revista da Sociedade Brasileira de Medicina Tropical 32: 605-611, 1999.

5. Ferreira AW, Ávila SLM. Diagnóstico Laboratorial das Principais Doenças Infecciosas e Auto-Imunes. Editora Guanabara Koogam, Rio de Janeiro, p. 127,2001

6. Gutierrez-Galhardo MC, Valle GF, Sá FC, Schubach AO, Valle AC. Clinical characteristics and evolution of syphilis in $24 \mathrm{HIV}+$ individuals in Rio de Janeiro, Brazil. Revista Instituto de Medicina Tropical de São Paulo 47: 153-157, 2005.

7. Melere R, Petry V, Fontana B, Marrone LCP. Sorologias em doadores de hemoconcentrados. Arquivos Médicos Canoas 1: 39-45, 2005.

8. Mendes KHC, Duartez G, Gir E, Aleixo YA, Capuano DM. Soropositividade para sífilis em amostras sanguineas, procedentes de quatro regiões (136 bairros) da cidade de Ribeirão Preto-SP. Medicina Ribeirão Preto 29: 123-129, 1996.

9. Ministério da Saúde. Manual de controle das doenças sexualmente transmissíveis. $4^{a}$ edição, 2006. Disponível em: http://www.aids.gov.br/data/Pages/Acessado em $10 / 06 / 2008$
10. Ministério da Saúde. Boletim Epidemiológico AIDS DST - ano II - $\mathrm{n}^{0} 1$. Disponível em: http://www.aids.gov.br/data/documents/Acessado em 10/06/2008.

11. Quattordio LE, Milani PL, Milani HL. Diagnóstico serológico de sífilis: Correlación de resultados según técnicas disponibles en el laboratorio. Acta Bioquímica Clínica Latinoamericana 38: 301-306, 2004

12. Sáez-Alquézar A, Albieri D, Garrini RHC, Marques WP, Lemos EA, Alves A. Desempenho de testes sorológicos para sífilis, treponêmicos (ELISA) e não treponêmicos (VDRL e RPR), na triagem sorológica para doadores de sangue - confirmação dos resultados por meio de três testes treponêmicos (FTA ABS, WB e TPHA). Revista de Patologia Tropical 36: 215-228, 2007.

13. Salles NA, Sabino EC, Barreto CC, Barreto AME, Otani MM, Chamone DF. Descarte de bolsas infecciosas em doadores de sangue da Fundação Pró-Sangue/Hemocentro de São Paulo. Revista Panamericana de Saúde Pública 13: 111-116, 2003.

14. Sanches LAT, Pittner E, Sanches HF, Monteiro MC. Detecção de casos novos de hanseníase no município de Prudentópolis, PR: 1998 á 2005. Revista da Sociedade Brasileira de Medicina Tropical 40: 541-545, 2007.

15. Santana LR, Parahyba MJPC, Alencar MJ, Marques DA. Teste VDRL para 0 diagnóstico da sífilis. Avaliação dos resultados em uma unidade de atenção primária de saúde. Revista Brasileira de Analises Clínicas 38: 71-73, 2006.

16. Signorini DJHP, Monteiro MCM, Sá CAM, Sionl FS, Neto HGL, Lima DPL, Machado JDC. Prevalência da co-infecção HIV-sífilis em um hospital universitário da cidade do Rio de Janeiro no ano de 2005. Revista da Sociedade Brasileira de Medicina Tropical 40: 282-285, 2007.

17. Souza EM. Há 100 anos, a descoberta do Treponema pallidum. Anais Brasileiros de Dermatologia 80: 547-548, 2005 